\title{
Preparation of TiAl-based alloys by induction melting in graphite crucibles
}

\author{
T. Čegan ${ }^{1,2} *$, I. Szurman ${ }^{1}$, M. Kursa ${ }^{1}$, J. Holešinský ${ }^{1}$, J. Vontorová ${ }^{1}$ \\ ${ }^{1}$ VS̆B-Technical University of Ostrava, Faculty of Metallurgy and Materials Engineering, Department of RMSTC, \\ 17. listopadu 15, 70833 Ostrava - Poruba, Czech Republic \\ ${ }^{2}$ Institute of Materials and Machine Mechanics, Slovak Academy of Sciences, \\ Račianska 75, 83102 Bratislava 3, Slovak Republic
}

Received 24 September 2014, received in revised form 25 September 2014, accepted 1 October 2014

\begin{abstract}
Three TiAl-based alloys with nominal composition Ti-47Al-8Nb, Ti-47Al-8Ta and Ti-47Al$-8 \mathrm{Ta}-0.3 \mathrm{Y}$ (at.\%) were prepared by induction melting in graphite crucibles and centrifugal casting into graphite moulds. Chemical composition, microstructure and mechanical properties of the as-cast alloys are characterised. The melting in the graphite crucible leads to an increase of carbon content from 460 to $1020 \mathrm{wtppm}$ and formation of fine carbide particles predominantly in the $\gamma(\mathrm{TiAl})$ phase. Beside fine carbides, the addition of 0.3 at.\% of yttrium results in formation of fine $\mathrm{Y}_{2} \mathrm{O}_{3}$ and $\mathrm{YAl}_{2}$ particles. The oxygen content depends on the chemical composition and varies between 330 and 780 wtppm for $\mathrm{Ta}$ and $\mathrm{Nb}$ containing alloys, respectively. The as-cast alloys exhibit relatively high values of room-temperature compression yield strength up to $922 \mathrm{MPa}$, ultimate compression strength up to $1793 \mathrm{MPa}$ and plastic deformation to fracture up to $24.3 \%$. The compression yield strength increases linearly with increasing Vickers microhardness of the as-cast alloys. From the point of view of chemical composition, microstructure and studied mechanical properties, induction melting in the graphite crucible and centrifugal casting into graphite mould can be considered as a suitable method of preparation of TiAl-based alloys.
\end{abstract}

K e y words: titanium aluminides, TiAl, induction melting, graphite crucible, microstructure, mechanical properties

\section{Introduction}

Permanent interest in reduction of weight and increase of efficiency of engines in the automotive, aerospace and power industries creates high needs for the development of new lightweight materials, which can withstand high temperatures while maintaining the acceptable mechanical properties. Nowadays, TiAl-based alloys represent unique group of materials, which is characterised by low density $\left(3.8-4.2 \mathrm{~g} \mathrm{~cm}^{-3}\right)$, high modulus of elasticity in a wide temperature range, good creep resistance, low diffusion coefficient, high melting point, good microstructural stability and good corrosion resistance. These properties predestine the TiAl-based intermetallics for use in heavyduty components for corrosive environments and high temperatures (up to $800^{\circ} \mathrm{C}$ ), where they can replace currently used nickel-based superalloys [1-6]. It took more than 20 years of intensive research before a mature level of these alloys was achieved, which allows using them in the aircraft, automotive and power engineering industries $[4,5]$. However, wide application of TiAl-based alloys is still hindered by their difficult preparation, high production cost, low ductility at room temperature and low formability. Among various processing techniques, precise casting offers the most cost effective method for production of complex shaped components from TiAl-based alloys $[4,5]$. Until now, no refractory material was found to be absolutely inert against these alloys and some interactions between melted alloy and crucible and mould materials always occurred during melting and casting [7-

*Corresponding author: tel. +420 777963 658; e-mail address: tomas.cegan@vsb.cz 
17]. These melt-ceramic material interactions lead to contamination and to degradation of some mechanical properties of cast components [10, 11]. From this reason skull melting processes in water cooled copper crucibles were applied to prevent melt contamination [18-20]. Although skull melting is capable to provide molten metal of high purity, it has a high impact on casting cost and high level of casting rejections, mainly due to difficulty to achieve optimal melt superheating, because much of the applied energy is lost to the water cooled crucible $[8,20]$. It is well known that the use of cheap crucible and mould refractory materials reduces significantly production cost of castings $[7,8,10]$. Numerous publications deal with the melting of TiAl-based alloys in ceramic crucibles made out of $\mathrm{Y}_{2} \mathrm{O}_{3}$ [9-11, 13, 14], $\mathrm{CaO}[7,8,10-12], \mathrm{Al}_{2} \mathrm{O}_{3}[10,12,14-16]$, $\mathrm{ZrO}_{2}[7,10]$ and others. However, there is a lack of information concerning melting of TiAl-based alloys in graphite crucibles. This type of crucible is of interest because of its low cost and high melting temperature. There is almost no available data describing contamination of TiAl-based alloys by carbon and carbides after melting in graphite crucibles and pouring into graphite moulds. Barbosa et al. [7] do not recommend induction melting of TiAl-based alloys in graphite crucibles because of contamination of products by carbon and carbides. In spite of the fact that the melting in graphite crucible leads to contamination by carbon and carbides, technically acceptable content of carbon can be achieved in TiAl-based alloys by a control of processing parameters during induction melting, especially by the control of maximum melt temperature and holding time between melt and graphite crucible [21].

The aim of the present work is to study the effect of induction melting in graphite crucible and centrifugal casting into graphite mould on chemical composition of three TiAl-based alloys with nominal composition Ti-47Al-8Nb, Ti-47Al-8Ta and Ti-47Al-8Ta$-0.3 \mathrm{Y}$ (at.\%). In addition, microstructure and mechanical properties of the studied as-cast alloys are characterised and potential of the applied procedure for preparation of TiAl-based alloys is discussed.

\section{Experiment}

\subsection{Graphite crucible and mould}

Density and open porosity of commercially available cold isostatic pressed graphite crucibles for induction melting with a diameter of $66 \mathrm{~mm} / 74 \mathrm{~mm}$ (inside/outside diameter) and length of $135 \mathrm{~mm}$ were measured using Archimedes principle, as described previously by Lapin et al. [13]. The crucible density $\left(\rho_{\mathrm{m}}\right)$, volume fraction of open porosity $\left(P_{\mathrm{o}}\right)$ and densification of crucible $D_{\mathrm{m}}$ were calculated according to
Ta ble 1. Measured properties of graphite crucible

\begin{tabular}{lc}
\hline Density $\rho_{\mathrm{m}}\left(\mathrm{g} \mathrm{cm}^{-3}\right)$ & $1.810 \pm 0.004$ \\
Volume fraction of open porosity & $1.2 \pm 0.7$ \\
$\quad P_{\mathrm{o}}($ vol.\%) & $80.1 \pm 0.2$ \\
\hline Densification $D_{\mathrm{m}}(\%)$ & \\
\hline
\end{tabular}

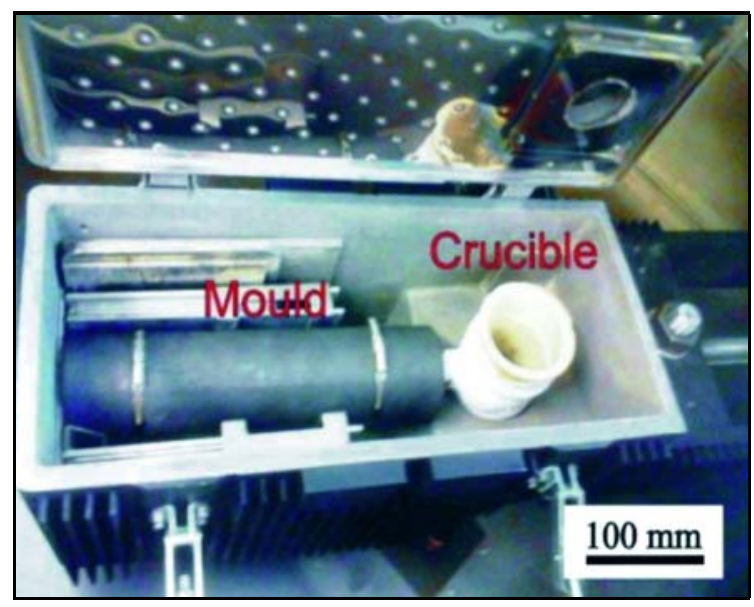

Fig. 1. Vacuum induction furnace for centrifugal casting equipped with ceramic crucible and graphite mould.

following equations:

$$
\begin{gathered}
\rho_{\mathrm{m}}=\frac{\rho_{\mathrm{w}} w_{2}}{w_{3}-w_{2}}, \\
P_{\mathrm{o}}=\frac{w_{3}-w_{1}}{w_{3}-w_{2}} \cdot 100, \\
D_{\mathrm{m}}=\frac{\rho_{\mathrm{m}}}{\rho_{\mathrm{t}}} \cdot 100,
\end{gathered}
$$

where $\rho_{\mathrm{w}}$ is the distilled water density $\left(0.998 \mathrm{~g} \mathrm{~cm}^{-3}\right)$, $\rho_{\mathrm{t}}$ is the theoretical density of the graphite $(2.26$ $\left.\mathrm{g} \mathrm{cm}^{-3}\right), w_{1}$ is the weight of the dried crucible, $w_{2}$ is the weight of the crucible immersed in distilled water, and $w_{3}$ is the weight of the crucible taken out of the distilled water. All measured properties of the crucible are summarised in Table 1.

Commercially available graphite mould with an outside diameter of $60 \mathrm{~mm}$ and length of $340 \mathrm{~mm}$ was used for casting, as seen in Fig. 1. The mould was made of extruded graphite with a bulk density of $1.75 \mathrm{~g} \mathrm{~cm}^{-3}$ and average porosity ranging from 17 to $20 \%$.

\subsection{Induction melting and centrifugal casting}

Three TiAl-based alloys with nominal composition Ti-47Al-8Nb, Ti-47Al-8Ta and Ti-47Al-8Ta-0.3Y 


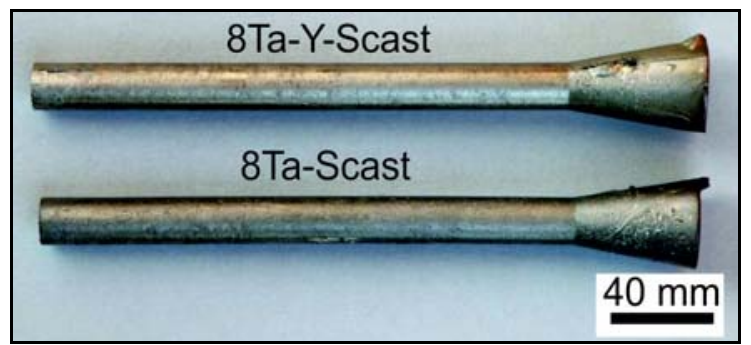

Fig. 2. Centrifugally cast Ti-47Al-8Ta and Ti-47Al-8Ta$-0.3 \mathrm{Y}($ at.\%) alloys.

(at.\%) were prepared by induction melting in graphite crucible and centrifugal casting into graphite mould. Charge composed of commercially pure pieces of titanium (99.99\%), aluminium (99.9\%), yttrium $(99.9 \%)$ and master alloys with nominal composition $\mathrm{Nb}-60 \mathrm{Al}$ (at.\%) or Ta-80Al (at.\%) was placed into the melting graphite crucible. The preparation, chemical compositions and melting temperatures of the master alloys were described elsewhere [22]. Melting of the charge was carried out in a medium frequency vacuum induction melting furnace Supercast - titan designed for induction melting of special alloys based on $\mathrm{Ti}, \mathrm{Ni}$, Fe and others [23-26]. The apparatus is equipped with a system for centrifugal casting, as shown in Fig. 1. The melting graphite crucible is held inside an alumina crucible. The alumina crucible serves as: (i) coil protection in the case of the graphite crucible failure and (ii) pouring lip for the melt into the graphite mould. Before the heating cycle, the chamber of the induction furnace was evacuated to a pressure of $1 \mathrm{~Pa}$ and then filled with Ar (99.9996 \%) up to a pressure of $20 \mathrm{kPa}$. This process was repeated three times to minimise oxygen content in the chamber. After reaching a melt temperature of $1700^{\circ} \mathrm{C}$, which was measured by optical pyrometer, the melted alloy was held at this temperature for $20 \mathrm{~s}$ to achieve full chemical homogenisation. Subsequently, the melted alloy was centrifugally cast into the graphite mould at a rotation speed of $270 \mathrm{rpm}$. Figure 2 shows the typical centrifugally cast ingots containing cylindrical part with a diameter of $20 \mathrm{~mm}$ and length of $225 \mathrm{~mm}$ and conical feeding head with a length of $70 \mathrm{~mm}$.

\subsection{Characterisation of as-cast alloys}

Samples for metallographic investigations were cut from the as-cast alloys by a diamond saw. Standard metallographic techniques such as grinding on $\mathrm{SiC}$ papers with grain sizes ranging from 80 to 2000 and polishing with $\mathrm{Al}_{2} \mathrm{O}_{3}$ suspensions with particle size changing from 1 to $0.3 \mu \mathrm{m}$ were applied. The samples were observed by scanning electron microscopy in the mode of back-scattered electrons (BSEM) and secondary electrons (SEM) using microscope QUANTA FEG
450 equipped with an energy dispersive spectrometer EDAX (EDS). EDS analysis was performed on two transversal sections taken from the bottom and upper part (below the feeding head) of each cast bar. Average chemical composition measured on specific transverse section of the bar was calculated from three independent measurements. X-ray diffraction analysis (XRD) was performed by diffractometer Bruker D8 using the database PDF-2 2004. Transmission electron microscopy (TEM) was performed by JEM-2100 microscope operating at $200 \mathrm{kV}$. Samples for TEM with an initial thickness of $0.3 \mathrm{~mm}$ were cut from the bars, thinned mechanically by grinding to a thickness of $100 \mu \mathrm{m}$ and finally thinned electrolytically in a solution composed of $6 \% \mathrm{HClO}_{4}$ and $94 \%$ ethanol using TenuPol-3 device operating at a voltage of $20 \mathrm{~V}$ and solution temperature of $-20^{\circ} \mathrm{C}$.

Samples for measurements of oxygen and carbon content with dimensions of $5 \times 5 \times 5 \mathrm{~mm}^{3}$ were cut from the as-cast bars and wet grinded on $\mathrm{SiC}$ papers with grain size of 600 . Oxygen content was measured by thermo-evolution method by analyser ELTRA ONH-2000. The measured sample was placed into a graphite crucible and heated in a resistance furnace under flowing helium. During melting oxygen reacts with the graphite and oxygen content in the sample is analysed in the form of $\mathrm{CO}$ and $\mathrm{CO}_{2}$ by infrared detector. Carbon content was measured by thermoevolution method by analyser ELTRA CS-2000. The measured sample was placed in a ceramic crucible and induction heated with tungsten under flowing oxygen. Tungsten serves as burning accelerator and carbon content is measured in the form $\mathrm{CO}$ and $\mathrm{CO}_{2}$ by infrared detector. Average content of oxygen and carbon in each as-cast bar was calculated from three independent measurements.

Vickers microhardness measurements were performed at a constant load of $0.1 \mathrm{~N}$ on polished and slightly etched cylindrical samples with a diameter of $20 \mathrm{~mm}$ and thickness of $5 \mathrm{~mm}$. Room-temperature compression tests were performed at an initial straining rate of $0.025 \mathrm{~s}^{-1}$ using universal testing machine Walter bai TMS LFV $100 \mathrm{kN}$. Rectangular compression specimens with dimensions of $4 \times 4 \times 8 \mathrm{~mm}^{3}$ were cut from the as-cast bars by electric discharge machining. The compression offset yield strength was measured at $0.2 \%$ plastic strain. The ultimate compression strength was determined as a maximum stress on strain-stress curve and plastic deformation to fracture was measured by an extensometer.

\section{Results and discussion}

\subsection{Chemical composition}

Table 2 shows the results of EDS analysis of the 
Table 2. EDS measurements of chemical composition of as-cast TiAl-based alloys

\begin{tabular}{lccccc}
\hline \multirow{2}{*}{ Alloy designation } & Nominal composition (at.\%) & \multicolumn{4}{c}{ Measured chemical composition (at.\%) } \\
\cline { 3 - 6 } & & $\mathrm{Ti}$ & $\mathrm{Al}$ & $\mathrm{Ta}(\mathrm{Nb})$ & $\mathrm{Y}$ \\
\hline 8Nb-Scast & Ti-47Al-8Nb & $43.52 \pm 0.76$ & $48.80 \pm 0.71$ & $7.69 \pm 0.13$ & 0 \\
8Ta-Scast & Ti-47Al-8Ta & $42.06 \pm 0.61$ & $49.66 \pm 0.99$ & $8.28 \pm 0.79$ & 0 \\
8Ta-Y-Scast & Ti-47Al-8Ta-0.3Y & $43.40 \pm 0.50$ & $47.59 \pm 1.09$ & $8.59 \pm 0.94$ & $0.41 \pm 0.06$ \\
\hline
\end{tabular}

Table 3. Measurements of oxygen and carbon content

\begin{tabular}{lcc}
\hline Alloy & Oxygen (wtppm) & Carbon (wtppm) \\
\hline 8Nb-Scast & $780 \pm 120$ & $800 \pm 99$ \\
8Ta-Scast & $330 \pm 50$ & $460 \pm 37$ \\
8Ta-Y-Scast & $460 \pm 82$ & $1020 \pm 42$ \\
\hline
\end{tabular}

as-cast alloys. The measured chemical compositions have relatively low standard deviations which indicates that the melt temperature and holding time on the melt temperature were sufficiently high and long, respectively, to achieve nearly homogeneous chemical composition of the castings. The values of standard deviations listed in Table 2 are comparable to other methods of preparation, e.g. with the ISM method, which offers similar ingot compositional guarantees of aluminium $\pm 0.75 \mathrm{wt} . \%$ and $\pm 0.5 \mathrm{wt} . \%$ for other elements $[27,28]$.

All prepared alloys show higher $\mathrm{Al}$ content than the nominal. The reason of increase of $\mathrm{Al}$ content is likely to be caused by a reaction of the melt with the graphite crucible leading to formation of a layer of titanium carbides or titanium and aluminium carbides on the crucible surface. Similar decrease of Ti was also observed during the melting of NiTi alloy in graphite crucibles, where the difference between nominal and measured content of Ti reached up to $4 \%$ [29]. It should be noted that Lapin and Frkáňová [30] observed lower content of $\mathrm{Al}$ than the nominal composition in Ti-Al-Ta alloys prepared by plasma melting in water cooled copper heart due to $\mathrm{Al}$ evaporation during melting. Differences in the content of $\mathrm{Ta}$ and $\mathrm{Nb}$ compared with the nominal composition can be explained also by differences in the content of elements in the master alloys used for melting [22]. Similar differences in Ta were also observed in plasma melted Ti-Al-Ta ingots prepared from Al-14Ta (\%) master alloy mixed with $\mathrm{Ti}$ sponge [30].

Table 3 shows measured contents of oxygen and carbon in the alloys. Generally, the alloys show a relatively low contamination by oxygen. However, in spite of using the identical parameters of melting and casting, the content of oxygen in each alloy is different. For example, the 8Ta-Scast alloy exhibits the lowest oxygen content of 330 wtppm, while the alloy $8 \mathrm{Nb}-$ -Scast contains up to $780 \mathrm{wtppm}$ of oxygen. The results clearly indicate that Ta containing TiAl-based alloys with low content of oxygen can be successfully prepared by melting in graphite crucibles and centrifugal casting into graphite moulds.

The carbon content measured in the as-cast alloys is relatively low when compared to that reported by Barbosa et al. [7]. The lowest carbon content of 460 wtppm is found in the 8Ta-Scast alloy, which corresponds to about 0.2 at.\%. This amount of carbon is usually used in alloy design to improve hightemperature mechanical properties of TiAl-based alloys through solid solution and precipitation strengthening [4, 28, 31-35]. However, the 8Nb-Scast and 8Ta-Y-Scast alloys contain up to $1020 \mathrm{wtppm}$ of carbon. Since the parameters of melting and casting (melt temperature, holding time of the melt, pouring time and mould temperature) were the same, the different content of carbon in the as-cast alloy was most likely caused by different heating time of the charge to the liquid state. In order to achieve more reproducible values of the carbon content in the induction melted alloys, it would be necessary to define precisely the size and distribution of charge components in the graphite crucible. However, such optimisation of the charge components and their distribution in the graphite crucible has not been carried out in this work.

\subsection{Microstructure}

Figures $3-5$ show the typical microstructures of the as-cast alloys. The typical dendritic microstructure is clearly shown in Figs. 3a, 4a and 5a. After centrifugal casting an average grain size is measured to be $(305 \pm 61) \mu \mathrm{m},(231 \pm 61) \mu \mathrm{m}$ and $(203 \pm 34) \mu \mathrm{m}$ for the $8 \mathrm{Nb}-\mathrm{Scast}$, $8 \mathrm{Ta}$-Scast and $8 \mathrm{Ta}$-Y-Scast alloys, respectively. The interlamellar $\alpha_{2}-\alpha_{2}$ spacing is measured to vary from 100 to $400 \mathrm{~nm}$. The results of EDS analysis of individual phases are summarised in Table 4. Bright colour phase forming a network within the dendrites (Figs. 3b, 4b and 5b) enriched by $\mathrm{Ti}, \mathrm{Nb}$, or Ta was identified to belong to remaining primary $\beta$ (Ti-based solid solution with cubic crystal structure) phase [30]. Figure 6 shows an example of XRD pattern for the as-cast 8Ta-Scast alloy confirming presence of $\alpha_{2}, \gamma$ and $\beta$ phases in the mi- 
Table 4. EDS analysis of individual phases in as-cast 8Nb-Scast, 8Ta-Scast and 8Ta-Y-Scast alloys (at.\%)

\begin{tabular}{lccc}
\hline $8 \mathrm{Nb}-\mathrm{Scast}$ & $\mathrm{Ti}$ & $\mathrm{Nb}$ & $\mathrm{Al}$ \\
\hline$\beta$ phase & $44.59 \pm 0.16$ & $9.27 \pm 0.48$ & $46.14 \pm 0.32$ \\
$\alpha_{2}+\gamma$ phase & $43.95 \pm 0.38$ & $8.27 \pm 0.48$ & $47.78 \pm 0.14$ \\
$\gamma$ phase & $43.21 \pm 0.67$ & $6.26 \pm 0.35$ & $50.53 \pm 0.89$ \\
\hline $8 \mathrm{Ta}-\mathrm{Scast}$ & $\mathrm{Ti}$ & $\mathrm{Ta}$ & $\mathrm{Al}$ \\
\hline$\beta$ phase & $42.65 \pm 0.54$ & $14.63 \pm 0.40$ & $42.72 \pm 0.93$ \\
$\alpha_{2}+\gamma$ phase & $42.26 \pm 0.09$ & $9.28 \pm 0.32$ & $48.46 \pm 0.23$ \\
$\gamma$ phase & $39.80 \pm 0.75$ & $2.51 \pm 0.44$ & $57.69 \pm 0.31$ \\
\hline 8 Ta-Y-Scast & $\mathrm{Ti}$ & $\mathrm{Ta}$ & $\mathrm{Al}$ \\
\hline$\beta$ phase & $43.04 \pm 0.17$ & $13.97 \pm 0.39$ & $42.99 \pm 0.26$ \\
$\alpha_{2}+\gamma$ phase & $43.26 \pm 0.09$ & $9.15 \pm 0.16$ & $47.56 \pm 0.13$ \\
$\gamma$ phase & $41.61 \pm 0.53$ & $3.18 \pm 0.29$ & $55.21 \pm 0.25$ \\
\hline
\end{tabular}
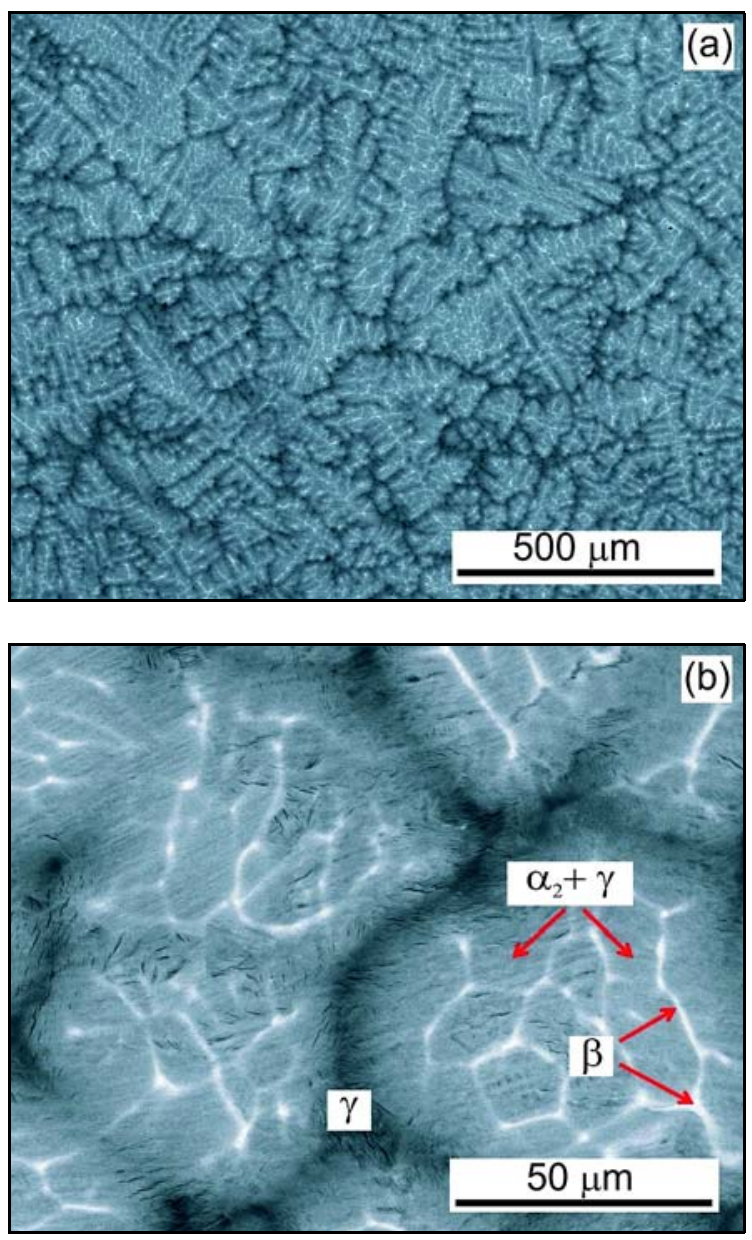

Fig. 3. BSEM micrographs showing microstructure of ascast $8 \mathrm{Nb}-$ Scast alloy: (a) dendritic microstructure; (b) remaining $\beta$ phase within the dendrites, lamellar $\alpha_{2}+\gamma$ region and interdendritic $\gamma$ phase.

crostructure. Generally, the observed amount of the $\beta$ phase is higher for the $8 \mathrm{Nb}$-Scast alloy than that
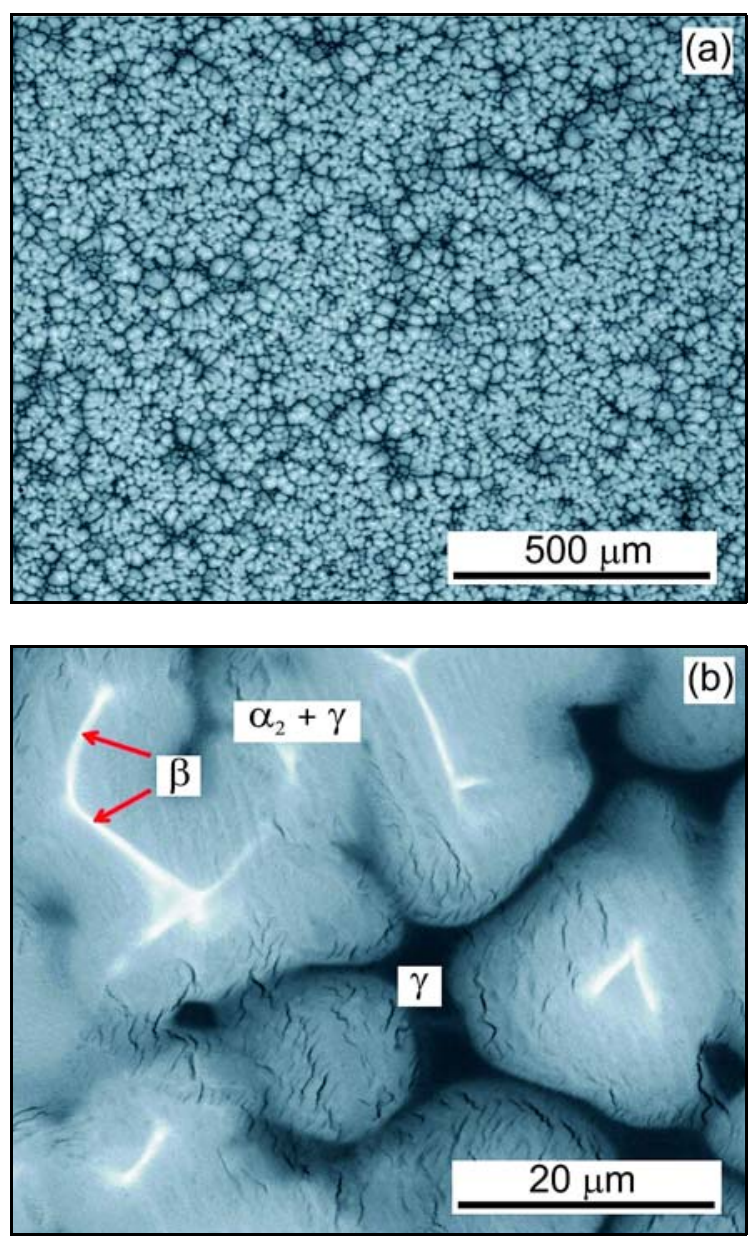

Fig. 4. BSEM micrographs showing microstructure of ascast 8Ta-Scast alloy: (a) dendritic microstructure; (b) remaining $\beta$ phase within the dendrites, lamellar $\alpha_{2}+\gamma$ region and interdendritic $\gamma$ phase.

of the 8Ta-Scast and 8Ta-Y-Scast alloys. The lamellar $\alpha_{2}\left(\mathrm{Ti}_{3} \mathrm{Al}\right)+\gamma(\mathrm{TiAl})$ microstructure is identified 

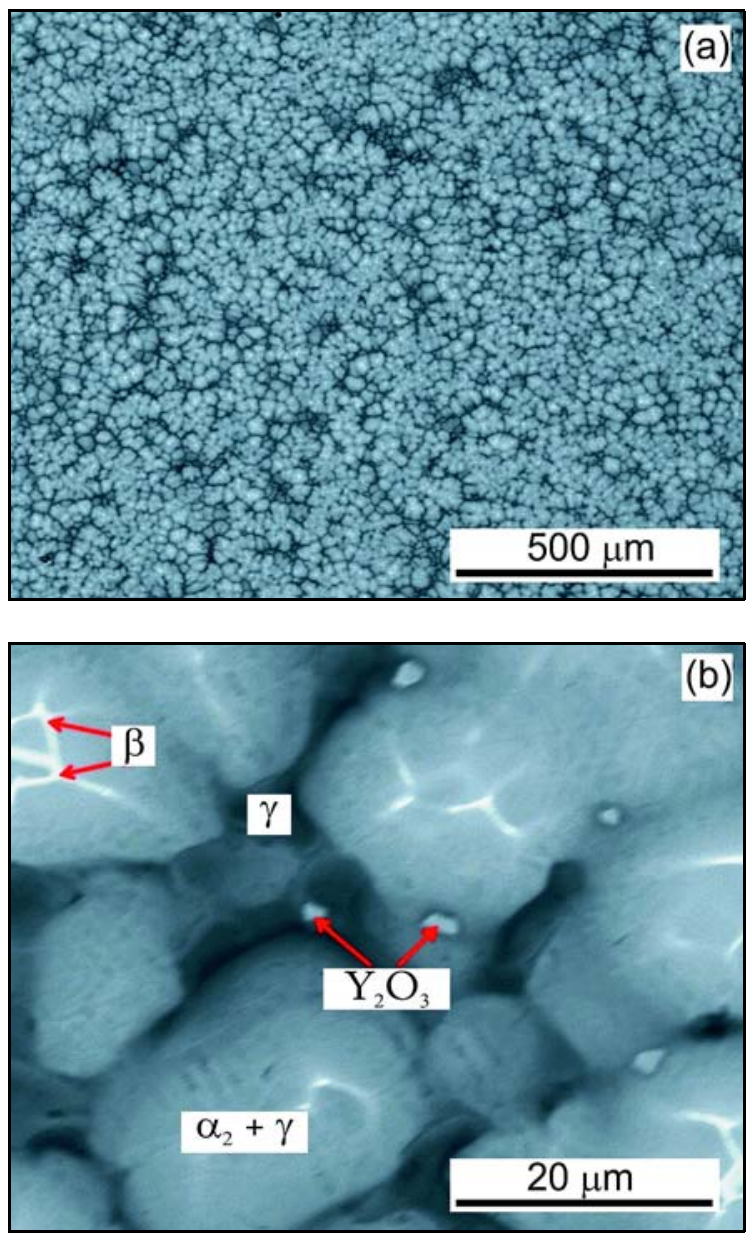

Fig. 5. BSEM micrographs showing microstructure of ascast $8 \mathrm{Ta}-\mathrm{Y}$-Scast alloy: (a) dendritic microstructure; (b) remaining $\beta$ phase within the dendrites, lamellar $\alpha_{2}+\gamma$ region and interdendritic $\gamma$ phase with $\mathrm{Y}_{2} \mathrm{O}_{3}$ particles.

within the dendrites and the $\gamma$ phase is observed in the interdendritic region, as marked in Figs. 3b, $4 \mathrm{~b}$ and 5b. The lamellar $\alpha_{2}+\gamma$ microstructure results from transformation of the primary $\beta$ phase to the $\alpha$ (Ti-based solid solution with hexagonal crystal structure) phase and precipitation of the $\gamma$ lamellae within the $\alpha$ phase, which transforms to ordered $\alpha_{2}$ phase at lower temperatures [36]. Figure 3a demonstrates the typical cubic symmetry of the dendrites, which was observed in all as-cast alloys. This cubic symmetry of the dendrites is the typical feature of TiAl-based alloys solidifying through $\beta$ primary phase [37]. White network of the remaining $\beta$ phase in the microstructure also supports the solidification of the studied alloys through the $\beta$ phase. Based on the microstructure observations, the solidification of the studied alloys can be defined as follows:

$$
L \rightarrow L+\beta,
$$

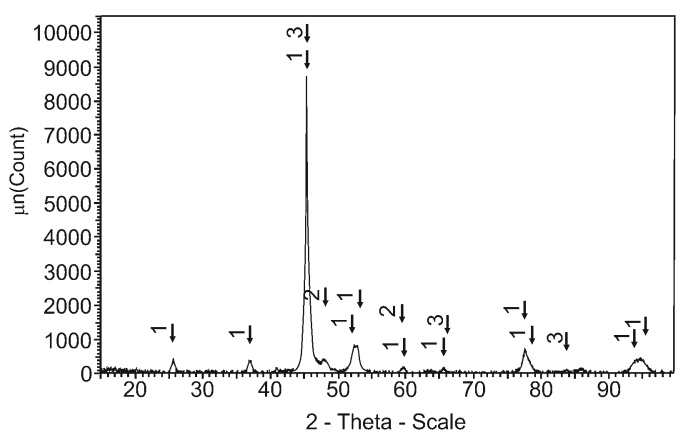

Fig. 6. Diffraction pattern of as-cast $8 \mathrm{Ta}-\mathrm{Y}$-Scast alloy: $1-\gamma$-TiAl, $2-\alpha_{2}-\mathrm{Ti}_{3} \mathrm{Al}, 3-\beta$-Ti.

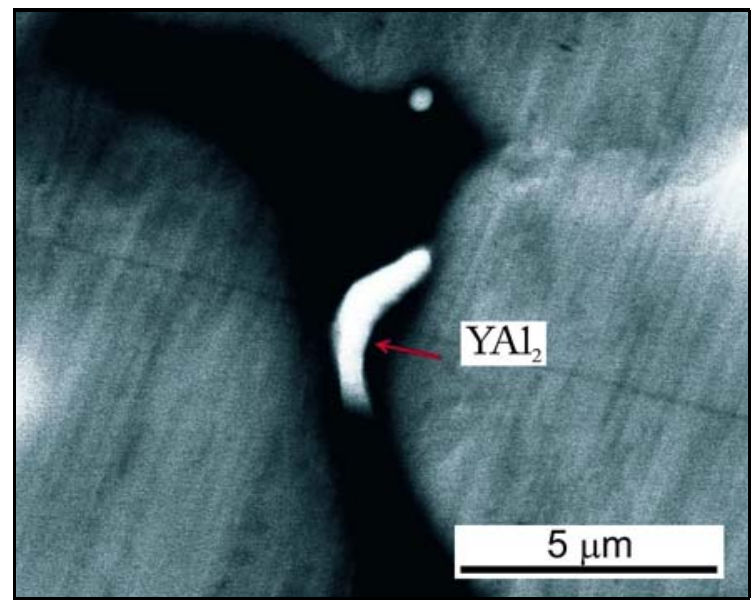

Fig. 7. BSEM micrograph showing $\mathrm{YAl}_{2}$ particle formed in the interdendritic $\gamma$ phase region of as-cast $8 \mathrm{Ta}$-Y-Scast alloy.

where $L$ is the liquid. The studied alloys show formation of peritectic $\alpha$ phase around the dendrites which was formed by a reaction:

$$
L+\beta \rightarrow \alpha
$$

Because of high cooling rate and low diffusivity of $\beta$ stabilizer elements, the peritectic reaction does not proceed fully during solidification of the studied alloys. Subsequently remaining interdendritic liquid enriched in $\mathrm{Al}$ solidifies finally as the $\gamma$ phase. During cooling the $\beta$ phase transforms to the $\alpha$ phase, which is unstable and transforms to lamellar $\alpha+\gamma$ microstructure in which the $\alpha$ phase transforms to an ordered $\alpha_{2}$ phase according to the binary phase diagram [38], as shown in Fig. 7. Similar solidification path, formation of peritectic $\alpha$ phase and solid phase transformations were recently described by Klimová et al. [34, 35].

Table 5 shows EDS analysis of yttrium-rich phases with the chemical composition corresponding to $\mathrm{Y}_{2} \mathrm{O}_{3}$ and $\mathrm{YAl}_{2}$. Although EDS analysis indicates presence of $\mathrm{Ti}$ and $\mathrm{Ta}$, this may be most likely caused by small 
Table 5. EDS analysis of yttrium rich phases (at.\%)

\begin{tabular}{lccccc}
\hline Phase & $\mathrm{Y}$ & $\mathrm{O}$ & $\mathrm{Al}$ & $\mathrm{Ti}$ & $\mathrm{Ta}$ \\
\hline $\mathrm{Y}_{2} \mathrm{O}_{3}$ & $21.33 \pm 2.75$ & $40.08 \pm 3.37$ & $22.11 \pm 3.58$ & $15.47 \pm 2.54$ & $1.01 \pm 1.01$ \\
$\mathrm{YAl}_{2}$ & $19.86 \pm 6.53$ & - & $58.53 \pm 2.84$ & $20.48 \pm 4.64$ & $1.13 \pm 1.09$ \\
\hline
\end{tabular}

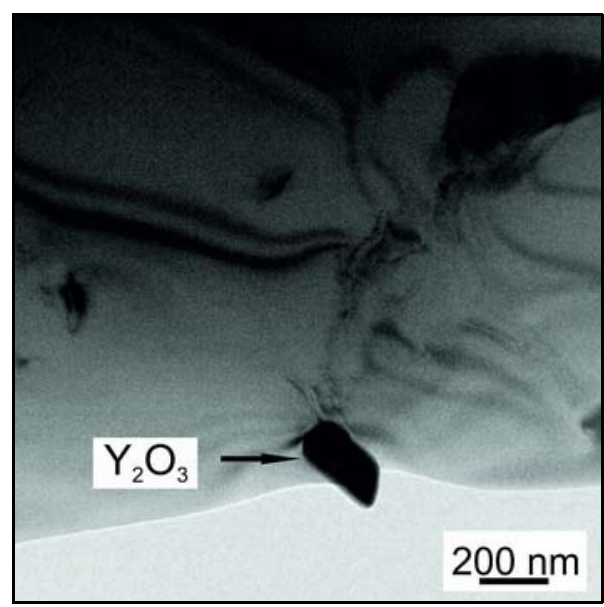

Fig. 8. TEM bright field micrograph of $\mathrm{Y}_{2} \mathrm{O}_{3}$ particle formed in the $\gamma$ phase of as-cast 8Ta-Y-Scast alloy.

Table 6. EDS analysis of small carbide particles (at.\%)

\begin{tabular}{cccc}
\hline $\mathrm{Ti}$ & $\mathrm{Al}$ & $\mathrm{Ta}(\mathrm{Nb})$ & $\mathrm{C}$ \\
\hline $27.12 \pm 4.65$ & $17.03 \pm 2.96$ & $2.32 \pm 0.16$ & $53.33 \pm 5.69$ \\
\hline
\end{tabular}

size of these particles and results of the measurements might be influenced by the surrounding matrix. The particles are preferentially distributed within the interdendritic region due to low solubility of yttrium in the $\beta$ and $\alpha$ phases [39]. The size and volume fraction of the particles are measured not to exceed $5 \mu \mathrm{m}$ and 1.2 vol. \%, respectively (Figs. $5,7,8$ ).

Table 6 summarises the results of EDS measurements of chemical composition of carbon rich particles, as shown in Figs. 9a,b. The content of $\mathrm{Ti}$ and $\mathrm{Al}$ in the particles is approximately $2: 1$ indicating that these fine particles probably belong to $\mathrm{Ti}_{2} \mathrm{AlC}$ phase. The carbides are found mainly in the $\gamma$ lamellae and in the interdendritic $\gamma$ phase. Their small size indicates that they were formed by precipitation from the solid $\gamma$ phase as a result of low solubility of interstitial carbon in TiAl (up to 0.02-0.03 at.\%) [40]. No fine carbides have been observed in the $\alpha_{2}$ phase, which shows much higher solubility of $\mathrm{C}$ than that of the $\gamma$ phase (up to 0.9 at.\%). It should be noted that no coarse carbide particles of acicular type are observed in the as-cast alloys. This suggests that the carbon content in the studied alloys is not sufficiently high for the forma-
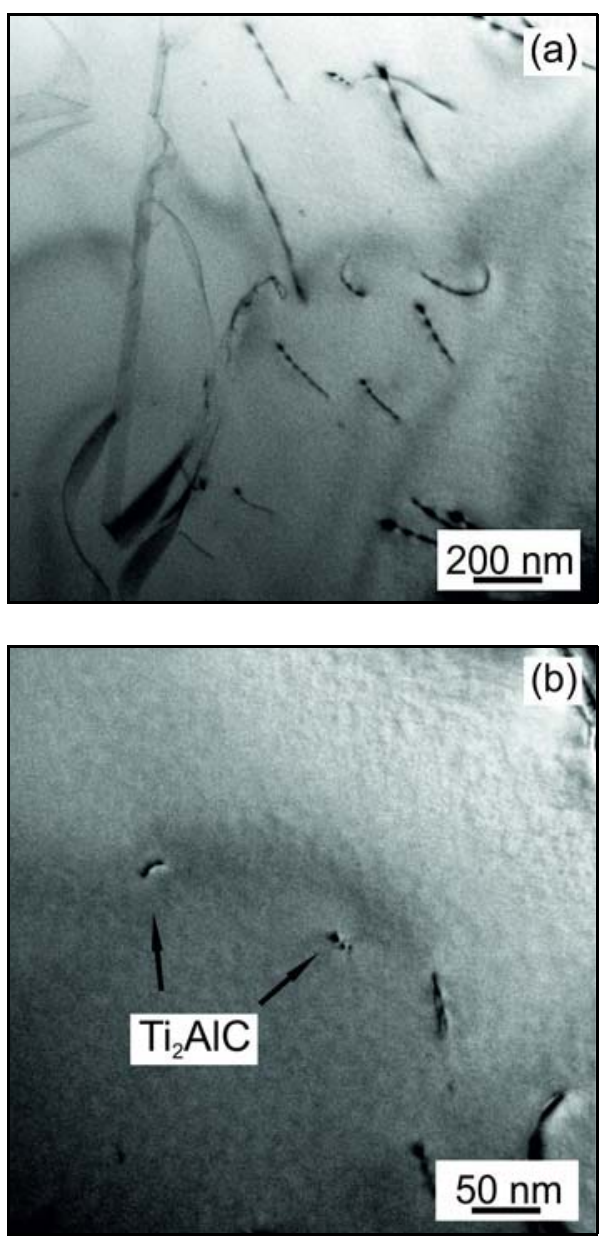

Fig. 9. TEM bright field micrographs of as-cast 8Ta-Scast: (a) dislocation pinning by carbide particles, (b) fine $\mathrm{Ti}_{2} \mathrm{AlC}$ precipitates in the $\gamma$ phase.

tion of coarse primary carbides directly from the melt $[41,42]$.

\subsection{Mechanical properties}

Figure 10 shows Vickers microhardness $\mathrm{HV}_{\mathrm{m}}$ evolution measured on transverse sections of centrifugally cast bars. The individual microhardness values strongly depend on the position in the bars and differ significantly from average values. The highest microhardness is measured in the remaining $\beta$ phase and the lowest values are found in the interdendritic $\gamma$ phase. The average Vickers microhardness values of the individual alloys also differ considerably. The 8Ta-Y- 


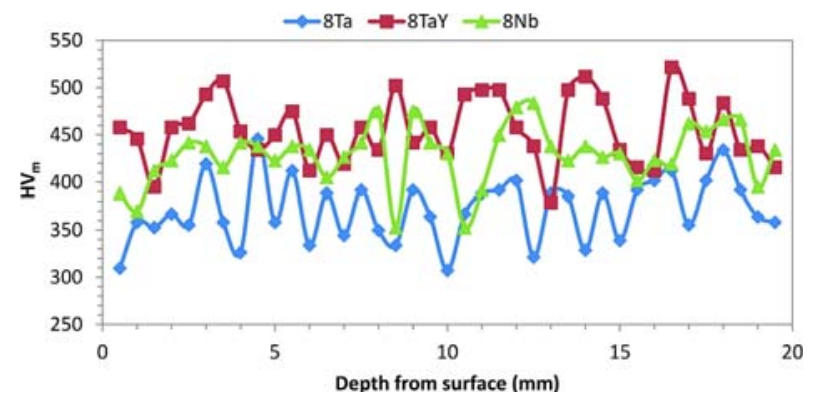

Fig. 10. Evolution of Vickers microhardness on transverse sections of centrifugally cast bars prepared from $8 \mathrm{Nb}-$ -Scast, 8Ta-Scast and 8Ta-Y-Scast alloys.

Table 7. Room-temperature compression properties of as-cast 8Nb-Scast, 8Ta-Scast and 8Ta-Y-Scast alloys

\begin{tabular}{lccc}
\hline Alloy & $R_{\mathrm{p}} 0.2(\mathrm{MPa})$ & $R_{\mathrm{m}}(\mathrm{MPa})$ & $\varepsilon_{\mathrm{Rm}}(\%)$ \\
\hline 8Nb-Scast & 852 & 1793 & 23.4 \\
8Ta-Scast & 795 & 1537 & 15.1 \\
8Ta-Y-Scast & 922 & 1791 & 17.3 \\
\hline
\end{tabular}

-Scast alloy exhibits the highest average value of $\mathrm{HV}_{\mathrm{m}}$ $=(456 \pm 35)$ and the 8Ta-Scast alloy shows the lowest value of $\mathrm{HV}_{\mathrm{m}}=(371 \pm 33)$. As shown recently by several authors $[8,9]$, the Vickers microhardness can be considered as a degree of the alloy contamination by intersticial elements resulting from melt-mould interactions during melting and casting processes. Perdrix et al. [40] reported a linear increase of microhardness with increasing carbon content up to about $1000 \mathrm{wtppm}$ in Ti-48Al (at.\%) alloy. This increase of the microhardness is caused by carbon solid solution strengthening of the $\alpha_{2}$ phase, because the $\gamma$ phase has low solubility limit and precipitation of small carbide particles in this phase does not significantly affect the microhardness [40]. Similar effect of carbon on microhardness was also observed by Schweighofer et al. [43] in TNM alloy. The differences in microhardness are also caused by different alloying elements. Vojtěch et al. [44] reported that Ta is more efficient solid solution strengthener than $\mathrm{Nb}$ which leads to higher microhardness of TiAl-based alloys modified with Ta when compared to that of $\mathrm{Nb}$ containing alloys.

Table 7 summarises the results of room-temperature compression strength, $0.2 \%$ offset yield strength and plastic deformation to fracture of the studied alloys. The alloys exhibit relatively high values of the yield strength ranging from 795 to $922 \mathrm{MPa}$, ultimate compression strength from 1537 to $1793 \mathrm{MPa}$ and plastic deformation to fracture from 15.1 to $24.3 \%$. For example, the values of plastic deformation to fracture are higher than those of 7-10\% measured for annealed Ti-45Al-8.5Nb-0.3W-0.05Y (at.\%) alloy pre-

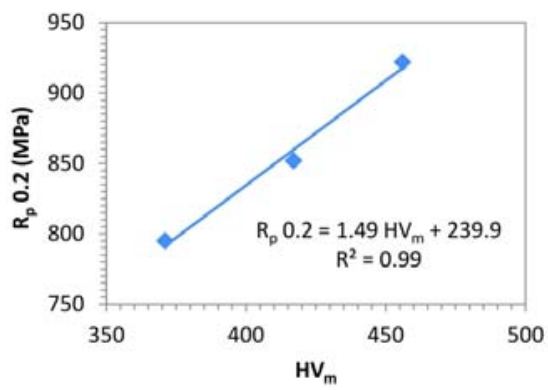

Fig. 11. Dependence of room-temperature $0.2 \%$ offset yield strength $R_{\mathrm{p}} 0.2$ on Vickers microhardnes $\mathrm{HV}_{\mathrm{m}}$.

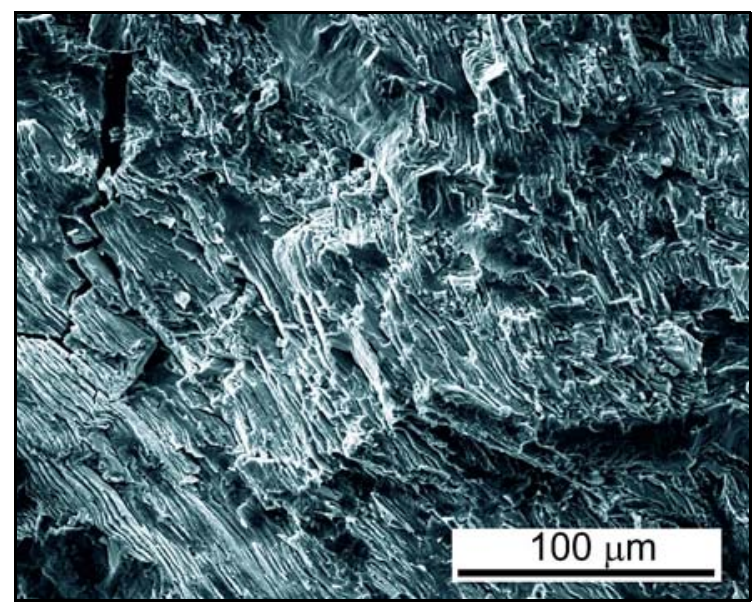

Fig. 12. Fracture surfaces of as-cast 8Ta-Scast alloy after room-temperature compression test.

pared by double vacuum arc remelting [45]. From the point of view of studied mechanical properties, melting of the studied alloys in graphite crucible and casting into graphite mould can be considered as a suitable method of their preparation.

Figure 11 shows dependence of compression yield stress on Vickers microhardness of the as-cast alloys. In spite of the different chemical composition of the studied alloy, the yield strength $R_{\mathrm{p}} 0.2$ increases linearly with increasing Vickers microhardness $\mathrm{HV}_{\mathrm{m}}$. Such linear dependence of the yield strength on the Vickers microhardness is in a good agreement with the results reported previously by Lapin et al. [46-48] for Ti-46Al-2W-0.5Si, Ti-46Al-8Nb (at.\%) and Ti-44Al-4Nb-4Zr-0.2Si-0.3B (at.\%) alloys. Linear regression analysis of the experimental data shown in Fig. 11 yields an equation in the form:

$$
R_{\mathrm{p}} 0.2=1.49 H V_{\mathrm{m}}+239.9 .
$$

The correlation coefficient of this fit is $r^{2}=0.99$. This equation indicates that the yield strength can be predicted from the simple Vickers microhardness measurements. 


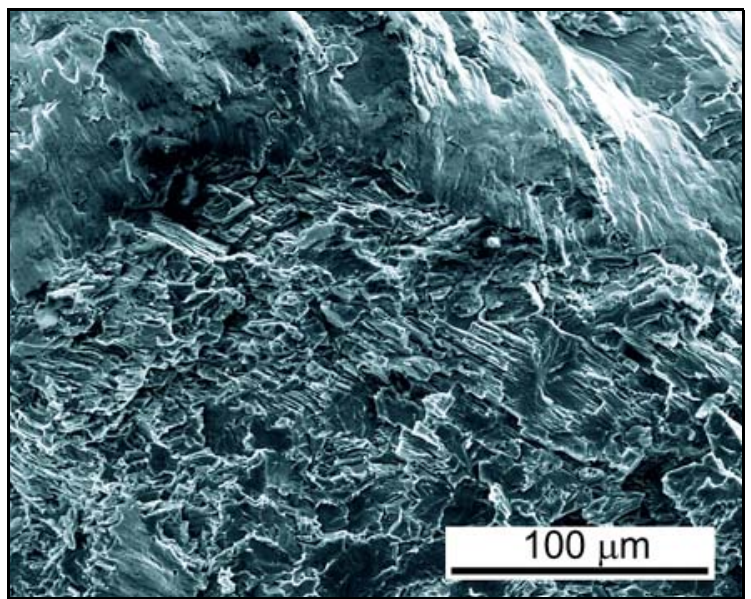

Fig. 13. Fracture surfaces of as-cast 8Ta-Y-Scast alloy after room-temperature compression test.

Figures 12 and 13 show fracture surfaces of the 8Ta-Scast and 8Ta-Y-Scast specimens after room temperature compression tests. The alloys exhibit mixed fracture mode containing transgranular fracture of lamellar $\alpha_{2}+\gamma$ grains and intergranular fracture along some lamellar grain boundaries. Propagation of crack within the lamellar grain in a direction perpendicular as well as parallel to the lamellar $\alpha_{2} / \gamma$ interfaces giving palisade type of fracture surface is well visible in Fig. 12. Figure 13 shows propagation of the crack with the lamellar grain and along the grain boundary.

\section{Conclusions}

Three TiAl-based alloys with nominal composition Ti-47Al-8Nb, Ti-47Al-8Ta and Ti-47Al-8Ta-0.3Y (at.\%) were successfully prepared by induction melting in graphite crucible and centrifugal casting into graphite mould. The melting in the graphite crucible increases carbon content and leads to formation of fine carbides predominantly in the $\gamma$ phase. Addition of 0.3 at.\% of yttrium results in formation of fine $\mathrm{Y}_{2} \mathrm{O}_{3}$ and $\mathrm{YAl}_{2}$ particles. The oxygen content depends on alloy composition and varies between 330 and 780 wtppm for $\mathrm{Ta}$ and $\mathrm{Nb}$ containing alloys, respectively. The as-cast alloys exhibit relatively high values of room-temperature compression yield strength up to $922 \mathrm{MPa}$, ultimate compression strength up to $1793 \mathrm{MPa}$ and plastic deformation to fracture up to $24.3 \%$. The compression yield strength increases linearly with increasing Vickers microhardness in the as-cast alloys. Melting in graphite crucible and casting into graphite mould can be considered as a suitable method of preparation of selected TiA-based alloys.

\section{Acknowledgements}

This article has been elaborated in the framework of the project No. LO1203 "Regional Materials Science and Technology Centre - Feasibility Program" funded by the Ministry of Education, Youth and Sports of the Czech Republic. This work is also based on the results of the project Center for Applied Research of New Materials and Technology Transfer, ITMS 26240220088, supported by the Science and Research Operational Program by the European Regional Development Fund. The authors would like to acknowledge the financial support of the Slovak Grant Agency for Science under the contract VEGA 2/0149/13.

\section{References}

[1] Loria, E. A.: Intermetallics, 8, 2000, p. 1339. doi:10.1016/S0966-9795(00)00073-X

[2] Tetsui, T.: Curr. Opin. Solid State Mat. Sci., 4, 1999, p. 243. doi:10.1016/S1359-0286(99)00023-6

[3] Appel, F., Oehring, M., Wagner, R.: Intermetallics, 8, 2000, p. 1283. doi:10.1016/S0966-9795(00)00036-4

[4] Lapin, J.: In: Procceding of International Conference on Metallurgy and Materials: Metal 2009. Eds.: Kliber, J., Kursa, M. Ostrava, TANGER Ltd. 2009, p. 20.

[5] Wu, X.: Intermetallics, 14, 2006, p. 1114. doi:10.1016/j.intermet.2005.10.019

[6] Lapin, J.: Kovove Mater., 43, 2005, p. 81.

[7] Barbosa, J., Silva Ribeiro, C.: Int. J. Cast Metals Res., 12, 2000, p. 293.

[8] Gomes, F., Barbosa, J., Silva Ribeiro, C.: Intermetallics, 16, 2008, p. 1292. doi:10.1016/j.intermet.2008.08.008

[9] Cui, R., Gao, M., Zhang, H., Gong, S.: J. Mater. Process. Technol., 210, 2010, p. 1190.

doi:10.1016/j.jmatprotec.2010.03.003

[10] Tetsui, T., Kobayashi, T., Ueno, T., Harada, H.: Intermetallics, 31, 2012, p. 274. doi:10.1016/j.intermet.2012.07.019

[11] Wang, L., Zheng, L., Cui, R., Yang, L., Zhang, H.: China Foundry, 9, 2011, p. 48.

[12] Kuang, J. P., Harding, R. A., Campbell, J.: Mater. Sci. Technol., 16, 2000, p. 1007. doi:10.1179/026708300101508964

[13] Lapin, J., Gabalcová, Z., Pelachová, T.: Intermetallics, 19, 2011, p. 396. doi:10.1016/j.intermet.2010.11.007

[14] Lapin, J., Gabalcová, Z.: Intermetallics, 19, 2011, p. 797. doi:10.1016/j.intermet.2010.11.021

[15] Lapin, J., Ondrúš, L.., Nazmy, M.: Intermetallics, 10, 2002, p. 1019. doi:10.1016/S0966-9795(02)00119-X

[16] Lapin, J., Ondrúš, L'.: Kovove Mater., 40, 2002, p. 161.

[17] Lapin, J., Nazmy, M.: Gamma Titanium Aluminides 2003. Eds.: Kim, Y.-W., Clemens, H., Rosenberger, A. H. Warrendale, TMS 2003, p. 185.

[18] Noda, T.: Intermetallics, 6, 1998, p. 709. doi:10.1016/S0966-9795(98)00060-0

[19] Zemčík, L., Dlouhý, A., Król, S., Prazmowski, M.: In: Proceedings of International Conference on Metallurgy and Materials: Metal 2005. Eds.: Kliber, J., Kursa, M. Ostrava, TANGER Ltd. 2005, p. 1.

[20] Harding, R. A.: Kovove Mater., 42, 2004, p. 225. 
[21] Cegan, T., Cagala, M., Kursa, M., Kawulok, P., Rusz, S., Juřica, J., Vontorová, J.: Materials and Technology, 48, 2014, p. 831.

[22] Juřica, J., Čegan, T., Skotnicová, K., Petlák, D., Smetana, B., Matějka, V.: In: Proceedings of International Conference on Materials and Technology. Ed.: Torkar, M. Ljubljana, IMT 2013, in press.

[23] Boyer, R. R.: Mater. Sci. Eng. A, 213, 1996, p. 103. doi:10.1016/0921-5093(96)10233-1

[24] Guo, J. T., Cui, C. Y., Qi, Y. H., Ye, H. Q.: J. Alloy. Compd., 343, 2002, p. 142. doi:10.1016/S0925-8388(02)00205-0

[25] Belbasi, M., Salehi, M. T., Seyedin, S. H.: Mater. Des., 49, 2013, p. 981. doi:10.1016/j.matdes.2013.01.070

[26] Skotnicová, K., Lasek, S., Kocich, R.: In: Proceedings of International Conference on Metallurgy and Materials: Metal 2012. Eds.: Kliber, J., Kursa, M. Ostrava, TANGER Ltd. 2012, p. 1574.

[27] Reed, S.: Gamma Titanium Aluminides. Warrendale, TMS 1995

[28] Appel, F., Paul, D. H., Oehring, M.: Gamma Titanium Aluminide Alloys. Weinheim, Wiley-VCH Verlag \& Co. KGaA 2011.

[29] Nayan, N., Govind-Saikrishna, C. N., Venkata Ramaiah, H., Bhaumik, S. K., Suseelan Nair, K., Mittal, M. C.: Mater. Sci. Eng. A, 465, 2007, p. 44. doi:10.1016/j.msea.2007.04.039

[30] Lapin, J., Frkáňová, K.: Kovove Mater., 49, 2011, p. 243.

[31] Appel, F., Brossmann, U., Christopf, U., Eggert, S., Janschek, P., Lorenz, U.: Adv. Eng. Mater., 2, 2000, p. 699. doi:10.1002/1527-2648(200011)2:11<699::AIDADEM699>3.0.CO;2-J

[32] Klimová, A., Gabalcová, Z., Lapin, J.: In: Proceedings of International Conference on Metallurgy and Materials: Metal 2013. Eds.: Kliber, J., Kursa, M. Ostrava, TANGER Ltd. 2013, p. 1328.

[33] Hecht, U., Witusiewicz, V., Drevermann, A., Zollinger, J.: Intermetallics, 16, 2008, p. 969. doi:10.1016/j.intermet.2008.04.019
[34] Lapin, J., Klimová, A., Gabalcová, Z.: Kovove Mater., 51, 2013, p. 147.

[35] Klimová, A., Lapin, J., Pelachová, T., Nosko, M.: Kovove Mater., 51, 2013, p. 89.

[36] Gabalcová, Z., Lapin, J.: Kovove Mater., 45, 2007, p. 231.

[37] Zollinger, J., Lapin, J., Daloz, D., Combeau, H.: Intermetallics, 15, 2007, p. 1343. doi:10.1016/j.intermet.2007.04.002

[38] Schuster, J. C., Palm, M.: J. Phase Equilib. Diffus., 27, 2006, p. 255. doi:10.1361/154770306X109809

[39] ASM Alloy Phase Diagram Database. Materials Park, ASM International 2006-2013.

[40] Perdrix, F., Trichet, M. F., Bonnentien, J. L., Cornet, M., Bigot, J.: Intermetallics, 9, 2001, p. 807. doi:10.1016/S0966-9795(01)00066-8

[41] Gouma, P. I., Davey, S. J., Loretto, M. H.: Mater. Sci. Eng. A, 241, 1998, p. 151. doi:10.1016/S0921-5093(97)00483-8

[42] McCullough, C., Valencia, J. J., Levi, C. G., Mehrabian, R.: Mater. Sci. Eng. A, 124, 1990, p. 83. doi:10.1016/0921-5093(90)90337-3

[43] Schweighofer, E., Rashkova, B., Clemens, H., Stark, A., Mayer, S.: Intermetallics, 46, 2014, p. 173. doi:10.1016/j.intermet.2013.11.011

[44] Vojtěch, D., Popela, T., Hamáček, J., Kützendörfer, J.: Mater. Sci. Eng. A, 528, 2011, p. 8557. doi:10.1016/j.msea.2011.07.070

[45] Yan, Y. Q., Zhang, Z. Q., Luo, G. Z., Wang, K. G., Zhou, L.: Mater. Sci. Eng. A, 280, 2000, p. 187. doi:10.1016/S0921-5093(99)00664-4

[46] Lapin, J., Ondrúš, L., Bajana, O.: Mater. Sci. Eng. A, 360, 2003, p. 85. doi:10.1016/S0921-5093(03)00445-3

[47] Lapin, J.: J. Mater. Sci. Lett., 22, 2003, p. 747. doi:10.1023/A:1023708110793

[48] Lapin, J., Gabalcová, Z., Bajana, O.: Kovove Mater., 47, 2009, p. 159. 